\title{
Controle de Plantas daninhas em Milho em Função de Épocas DE APLiCAÇÃo de Nitrogênio ${ }^{1}$
}

\author{
Weed Control in Maize in Function of Nitrogen Application Time
}

RIZZARDI, M.A. ${ }^{2}$, ZANATTA, F.S. ${ }^{3}$, LAMB, T.D. $^{4}$ e JOHANN, L.B. ${ }^{4}$

\begin{abstract}
RESUMO - Objetivou-se neste trabalho avaliar a influência da época de aplicação do nitrogênio nas relações de interferência das plantas daninhas na cultura do milho e determinar o efeito da aplicação de nitrogênio na época de controle destas. O delineamento experimental foi o de blocos casualizados, com os tratamentos arranjados em parcelas subdivididas, com quatro repetições. Os tratamentos consistiram de cinco sistemas de aplicação de nitrogênio em milho: 0-0-0, 150-0-0, 75-75-0, 0-150-0 e 0-75-75, correspondendo, respectivamente, às quantidades de nitrogênio aplicadas em pré-semeadura, nos estádios de quatro e oito folhas, e de seis épocas de controle de plantas daninhas (milho com 2, 3, 4, 5, 6 e 7 folhas) mais duas testemunhas sem e com a presença de ervas. Realizou-se o controle de plantas daninhas em pós-emergência com a associação dos herbicidas nicosulfuron e atrazine. $\mathrm{O}$ controle de plantas daninhas no estádio fenológico $\mathrm{V}_{2}$ do milho resultou em menor controle da erva em função da reinfestação. Aplicações antecipadas do nitrogênio aumentaram a densidade das plantas daninhas. Os maiores teores de nitrogênio na folha-indice do milho ocorreram quando ele foi aplicado nos estádios $V_{4}$ e $V_{8}$ desta cultura, independentemente da época de controle das plantas daninhas. O maior rendimento de grãos e o número de grãos por espiga de milho foram obtidos quando o controle das plantas daninhas foi realizado no estádio fenológico $\mathrm{V}_{4}$ da cultura, independentemente da época de aplicação do nitrogênio.
\end{abstract}

Palavras-chave: Zea mays, manejo, interferência, adubação.

\begin{abstract}
The objective of this study was to evaluate the influence of nitrogen application time on weed interference in maize and to determine nitrogen application effect on weed control. The trial was conducted in completely randomized blocks and split-plot design, with four replications. The treatments consisted of five systems of nitrogen application on maize: 0-0-0, 150-0-0, 75-75-0, $0-150-0$ and $0-75-75$, corresponding, respectively, to the applied amounts of nitrogen before sowing with four and eight leaves, and six times of weed control (maize with 2, 3, 4, 5, 6 and 7 leaves) plus two controls with and without the presence of weeds. The chemical control of weeds was performed after emergence by associating the herbicides nicosulfuron and atrazine. The weed control in $V_{2}$ was not efficient due to re-infestation. Anticipated applications of nitrogen increased weed density. The greatest nitrogen levels in the index-leaf occurred when nitrogen was applied in $V_{4}$ and $V_{8}$, regardless of weed control time. The highest grain yield and number by corn ear were obtained after weed control was performed at the phenological stage $V$, regardless of nitrogen application time.
\end{abstract}

Keywords: Zea mays, management, interference, fertilization.

1 Recebido para publicação em 26.4.2007 e na forma revisada em 4.1.2008

2 Engo-Agro-., Prof. da Faculdade de Agronomia e Medicina Veterinária - UPF, Bolsista do CNPq, Caixa Postal 611, 99001-970, Passo Fundo, RS, <rizzardi@upf.br>; ${ }^{3}$ Engo-A - grr ${ }^{\circ}$., Aluno do Programa de Pós-Graduação em Agronomia - UPF; ${ }^{4}$ Acadêmicos do Curso de Agronomia, UPF. Bolsistas de Iniciação Científica do CNPq e Fapergs.

Planta Daninha, Viçosa-MG, v. 26, n. 1, p. 113-121, 2008 


\section{INTRODUÇÃO}

A fertilização nitrogenada é um dos principais fatores para que a cultura do milho expresse seu potencial máximo de rendimento. A época de aplicação do fertilizante nitrogenado constitui-se em importante estratégia para se obter maior eficiência na absorção deste nutriente pelo milho (DiTomaso, 1995). O fato de os fertilizantes nitrogenados não se acumularem no solo, na mesma proporção dos outros macronutrientes, faz com que seja necessário o seu manejo para reduzir perdas e, assim, obter o máximo rendimento da cultura, quando na presença de plantas daninhas (Walker \& Buchanan, 1982).

As perdas no rendimento de grãos da cultura do milho variam com as espécies das plantas daninhas presentes e com a época de aplicação do nitrogênio (Harbur \& Owen, 2004). O rendimento de grãos na presença de Setaria faberi foi maior quando o nitrogênio foi aplicado em pré-semeadura, comparado com a aplicação em pós-emergência do milho, no estádio $\mathrm{V}_{7}$ (Harbur \& Owen, 2004).

Em trigo, na presença de Bromus tectorum, a aplicação do nitrogênio em pós-semeadura, no perfilhamento, reduziu o rendimento de grãos, em relação à aplicação na pré-semeadura, 21 dias antes da semeadura (Ball et al., 1996). No girassol, o rendimento de grãos diminuiu linearmente à medida que se atrasou a aplicação do nitrogênio do estádio $V_{4}$ para o estádio fenológico $R_{3}$, tanto na presença quanto na ausência das plantas daninhas (Fleck \& Silva, 1989). Nas culturas do trigo e do triticale, a aplicação parcelada do nitrogênio, quando comparada com a sua aplicação em pré-semeadura, reduziu o rendimento de grãos das culturas na presença de Avena sterilis (Dhima \& Eleftherohorinos, 2001).

Além da época de aplicação do nitrogênio, a habilidade competitiva das culturas varia com a espécie de planta daninha presente. Paolini et al. (1999) relataram que a cultura da beterraba-açucareira foi favorecida pela aplicação de nitrogênio aos 56 dias após emergência da cultura, na presença de Sinapis arvensis, e pela aplicação aos 28 dias após emergência da cultura, na presença de Chenopodium album.
O teor de nitrogênio nas plantas pode ser alterado em função da época de aplicação do nutriente. Nesse aspecto, a concentração do nitrogênio nas folhas do milho e das plantas daninhas foi maior com a aplicação em présemeadura, em relação à aplicação em pósemergência da cultura (Harbur \& Owen, 2004). $\mathrm{Na}$ cultura do trigo, o teor de nitrogênio em Chenopodium album foi maior quando o nutriente foi aplicado na pré-semeadura, comparado com a aplicação na semeadura da cultura (Blackshaw et al., 2004).

Em diferentes épocas de aplicação de nitrogênio, a produção da matéria seca de Bromus tectorum aumentou quando esse nutriente foi aplicado no perfilhamento do trigo, em relação ao tratamento cuja aplicação foi em pré-semeadura (Ball et al., 1996). No milho, as plantas daninhas apresentaram maior produção da matéria seca com a aplicação do nitrogênio em pré-semeadura, quando comparada com a aplicação em pós-emergência do milho (Harbur $\&$ Owen, 2004).

O efeito da adubação nitrogenada na interação cultura-planta daninha ainda é pouco conhecido, particularmente quando as épocas de aplicação do nitrogênio estiverem associadas às épocas de controle das plantas daninhas. Diante do exposto, há necessidade de pesquisas para identificar esses efeitos, no sentido de otimizar o uso do nitrogênio e, também, o controle das plantas daninhas. Os objetivos deste trabalho foram avaliar a influência das épocas de aplicação do nitrogênio nas relações de interferência das plantas daninhas na cultura do milho e determinar o efeito da aplicação do nitrogênio na época de controle dessas plantas.

\section{MATERIAL E MÉTODOS}

O experimento foi conduzido na área experimental de herbologia, no Centro de Extensão e Pesquisa Agropecuária da Faculdade de Agronomia e Medicina Veterinária da Universidade de Passo Fundo, localizada no Planalto Médio do Rio Grande do Sul.

O solo foi classificado como Latossolo Vermelho distrófico típico. Antecedendo a semeadura, foi coletada uma amostra de solo, na profundidade de 0 a $20 \mathrm{~cm}$. Os resultados da análise de solo foram os seguintes: argila $=46 \%$; 
$\mathrm{MO}=2,6 \% ; \mathrm{pH} \mathrm{em}_{2} \mathrm{O}=5,4 ; \mathrm{P}=20 \mathrm{mg} \mathrm{dm}^{-3}$; $\mathrm{K}=155 \mathrm{mg} \mathrm{dm}^{-3} ; \mathrm{Al}=0,0 \mathrm{cmolc} \mathrm{dm}^{-3}, \mathrm{Ca}=$ $5,9 \mathrm{cmolc} \mathrm{dm}^{3}, \mathrm{Mg}=3,1 \mathrm{cmolc} \mathrm{dm}^{-3} ; \mathrm{H}+\mathrm{Al}=$ $4,7 \mathrm{cmol}_{\mathrm{c}} \mathrm{dm}^{-3} ; \mathrm{CTC}=14,1 \mathrm{cmol}_{\mathrm{c}} \mathrm{dm}^{-3}$; saturação de bases $=66 \% ; \mathrm{S}=19 \mathrm{mg} \mathrm{dm}^{-3} ; \mathrm{B}=$ $0,5 \mathrm{mg} \mathrm{dm}^{-3} ; \mathrm{Mn}=14,3 \mathrm{mg} \mathrm{dm}^{-3} ; \mathrm{Zn}=$ $0,8 \mathrm{mg} \mathrm{dm}^{-3} ; \mathrm{e} \mathrm{Cu}=2,1 \mathrm{mg} \mathrm{dm}^{-3}$.

O delineamento experimental foi de blocos casualizados, com os tratamentos dispostos em parcelas subdivididas. As parcelas principais constituíram-se das épocas de aplicação do nitrogênio, e as subparcelas, das épocas de controle das plantas daninhas. Foram utilizadas quatro repetições, e cada unidade experimental media $2,8 \times 4,5 \mathrm{~m}\left(12,6 \mathrm{~m}^{2}\right)$.

$\mathrm{O}$ fator épocas de aplicação de nitrogênio foi composto por cinco sistemas de manejo da adubação nitrogenada (0-0-0, 150-0-0, 75-750, 0-150-0 e 0-75-75), em que o primeiro, o segundo e o terceiro número, em cada sistema, referem-se, respectivamente, às doses de nitrogênio $\left(\mathrm{kg} \mathrm{ha}^{-1}\right)$ aplicadas a lanço em présemeadura (sete dias antes da semeadura), no estádio $V_{4}$ (quatro folhas do milho totalmente expandidas) e no estádio $V_{8}$ (oito folhas do milho totalmente expandidas).

O fator épocas de controle de plantas daninhas constituiu-se da aplicação de herbicida aos $7,14,21,28,35$ e 42 dias após a emergência (DAE) do milho, cujos estádios fenológicos correspondiam a $V_{2}$ (duas folhas do milho totalmente expandidas), $V_{3}$ (três folhas do milho totalmente expandidas), $V_{4}$ (quatro folhas do milho totalmente expandidas), $\mathrm{V}_{5}$ (cinco folhas do milho totalmente expandidas), $\mathrm{V}_{6}$ (seis folhas do milho totalmente expandidas) e $\mathrm{V}_{7}$ (sete folhas do milho totalmente expandidas), respectivamente. Foram mantidas duas testemunhas, uma na presença e outra na ausência das plantas daninhas, em que a eliminação foi realizada com o controle químico aos $7 \mathrm{DAE}$ do milho e, posteriormente, com capina manual.

A semeadura direta do milho foi realizada sobre a palha de aveia-preta (Avena strigosa). $\mathrm{O}$ manejo da aveia foi feito com o herbicida glyphosate (900 $\left.\mathrm{g} \mathrm{ha}^{-1}\right)$, utilizando-se pulverizador costal pressurizado e volume de calda equivalente a $200 \mathrm{~L} \mathrm{ha}{ }^{1}$.

As sementes de milho foram tratadas com carboxin + thiram (Vitavax + Thiram $200 \mathrm{~g}$
$100 \mathrm{~kg}$ sementes ${ }^{-1}$ ) e alfacyoermetrin (Fastac a $0,02 \mathrm{~L} \mathrm{~kg}^{-1}$ de semente). Antes da semeadura, a adubação do solo foi realizada nos sulcos, com $20 \mathrm{~kg} \mathrm{ha}^{-1}$ de $\mathrm{N}, 100 \mathrm{~kg}$ ha ${ }^{1}$ de $\mathrm{P}_{2} \mathrm{O}_{5}$ e $100 \mathrm{ha}^{-1} \mathrm{de} \mathrm{K}_{2} \mathrm{O}$. O milho híbrido Flash foi semeado manualmente, na densidade de 60.000 plantas ha ${ }^{-1}$, colocando-se duas a três sementes por cova. Após a emergência do milho fez-se o desbaste manual, deixando uma planta por cova. O nitrogênio foi distribuído a lanço, na forma amídica (uréia), nas épocas estabelecidas para cada tratamento.

A área onde o experimento foi instalado apresentava infestação mista de plantas daninhas. O levantamento botânico indicou as seguintes espécies presentes: Brachiaria plantaginea (papuã), 60\%; Bidens pilosa (picãopreto), 21\%; Digitaria horizontalis (milhã), 9\%; Euphorbia heterophylla (leiteira), 6\%; Ipomoea spp. (corda-de-viola), 2\%; Sida spp. (guanxuma), 1\%; e Amaranthus ssp. (caruru), 1\%.

O controle das plantas daninhas foi realizado em pós-emergência, com os herbicidas nicosulfuron e atrazine (Sanson $0,8 \mathrm{~L} \mathrm{ha}^{-1} \mathrm{e}$ Primóleo 3,0 L ha' ${ }^{-1}$ ). Na aplicação foi utilizado pulverizador costal pressurizado a $\mathrm{CO}_{2}$, com pontas de jato plano XR 110.03 , em pressão constante de $200 \mathrm{kPa}$ e volume da calda equivalente a $200 \mathrm{~L}$ ha ${ }^{1}$.

A contagem do número de plantas daninhas foi realizada na testemunha na ausência de controle, em área de $0,125 \mathrm{~m}^{2}$. A contagem teve início aos sete dias após a emergência do milho; as contagens subseqüentes foram realizadas a cada sete dias, finalizando aos 70 dias após a primeira contagem.

O controle das plantas daninhas foi avaliado por escala visual aos 7, 14 e 21 dias após a aplicação (DAA) dos herbicidas, atribuindo-se percentuais de controle das plantas daninhas em relação à testemunha sem controle, em que a nota zero correspondeu a nenhum efeito de controle e a nota 100 significou morte completa das plantas daninhas.

No florescimento das plantas de milho foi determinada a matéria seca das plantas daninhas, com a coleta de amostras de $0,25 \mathrm{~m}^{2} \mathrm{em}$ cada subparcela. As amostras foram levadas à estufa de ventilação forçada, em temperatura de $60{ }^{\circ} \mathrm{C}$, até peso constante por 72 horas. Também nessa época foi determinado o teor de 
nitrogênio na folha-índice do milho. Foram coletadas cinco folhas inteiras, posicionadas abaixo das espigas. Estas amostras foram secas em estufa com circulação forçada de ar a $70^{\circ} \mathrm{C}$ e posteriormente analisadas.

A estatura das plantas de milho e a altura de inserção das espigas foram determinadas nas duas linhas centrais das subparcelas, em dez plantas, escolhidas aleatoriamente, após o florescimento da cultura.

A colheita do milho foi realizada nas duas linhas centrais das subparcelas. Antes da colheita contou-se o número de espigas por planta. As espigas colhidas foram trilhadas e os grãos pesados, obtendo-se então o rendimento de grãos, corrigido para 13\% de umidade. Avaliaram-se ainda o peso de mil grãos e o número de grãos por espiga.

Os dados foram submetidos à análise de variância e testados pelo teste F. Quando significativos $(\mathrm{P}<0,05)$, procedeu-se à análise comparativa, a $5 \%$ de probabilidade. Nas interações utilizou-se a probabilidade de $15 \%$. A fim de comparar os efeitos de controle, procedeuse à análise de regressão para a respectiva variável resposta, sendo utilizados os modelos polinomiais de primeiro e segundo graus para ajustar a distribuição dos dados obtidos. Os dados percentuais relativos ao controle das plantas daninhas foram normalizados pela transformação em raiz quadrada de $(\mathrm{x}+1)$, para realização da análise de variância.

\section{RESULTADOS E DISCUSSÃO}

Ao analisar os resultados de controle de plantas daninhas, não se observou interação das épocas de aplicação de nitrogênio e épocas de controle, tampouco o efeito simples das épocas de aplicação de nitrogênio, tanto para picão-preto quanto para papuã (Tabela 1). A variável controle somente foi influenciada pelas épocas de controle.

As porcentagens de controle de papuã situaram-se entre 82 e $98 \%$, naqueles tratamentos em que se efetuou o controle da planta daninha (Tabela 1). Aos 7 dias após a aplicação dos herbicidas (DAA), as menores porcentagens de controle foram observadas nas aplicações realizadas quando o milho se encontrava nos estádios fenológicos de $\mathrm{V}_{4}$ a $\mathrm{V}_{7}$. Na avaliação
Tabela 1 - Porcentagem de controle de papuã (Brachiaria plantaginea) e picão-preto (Bidens pilosa) em função das épocas de controle de plantas daninhas, na média das épocas de aplicação de nitrogênio

\begin{tabular}{|l|c|c|c|}
\hline \multirow{2}{*}{ Época de controle } & \multicolumn{3}{|c|}{ Controle de papuã (\%) } \\
\cline { 2 - 4 } & $7 \mathrm{DAA}^{1}$ & $14 \mathrm{DAA}$ & $21 \mathrm{DAA}$ \\
\hline Sem plantas daninhas & $100 \mathrm{a}$ & $100 \mathrm{a}$ & $100 \mathrm{a}$ \\
\hline Sem controle & $0 \mathrm{~d}$ & $0 \mathrm{c}$ & $0 \mathrm{e}$ \\
\hline Estádio $\mathrm{V}_{2}$ & $95 \mathrm{ab}$ & $98 \mathrm{a}$ & $89 \mathrm{~cd}$ \\
\hline Estádio $\mathrm{V}_{3}$ & $96 \mathrm{ab}$ & $99 \mathrm{a}$ & $98 \mathrm{ab}$ \\
\hline Estádio $\mathrm{V}_{4}$ & $92 \mathrm{bc}$ & $95 \mathrm{a}$ & $96 \mathrm{abc}$ \\
\hline Estádio $\mathrm{V}_{5}$ & $89 \mathrm{c}$ & $89 \mathrm{~b}$ & $94 \mathrm{bc}$ \\
\hline Estádio $\mathrm{V}_{6}$ & $88 \mathrm{c}$ & $85 \mathrm{~b}$ & $82 \mathrm{~d}$ \\
\hline Estádio $\mathrm{V}_{7}$ & $88 \mathrm{c}$ & $85 \mathrm{~b}$ & $84 \mathrm{~d}$ \\
\hline CV (\%) & 5,01 & 8,05 & 8,32 \\
\hline \multirow{2}{*}{ Época de controle } & $\mathrm{Controle}$ de picão-preto (\%) \\
\cline { 2 - 4 } & $7 \mathrm{DAA}{ }^{1}$ & $14 \mathrm{DAA}$ & $21 \mathrm{DAA}$ \\
\hline Sem plantas daninhas & $100 \mathrm{a}$ & $100 \mathrm{a}$ & $100 \mathrm{a}$ \\
\hline Sem controle & $0 \mathrm{c}$ & $0 \mathrm{~b}$ & $0 \mathrm{~b}$ \\
\hline Estádio $\mathrm{V}_{2}$ & $89 \mathrm{~b}$ & $98 \mathrm{a}$ & $99 \mathrm{a}$ \\
\hline Estádio $\mathrm{V}_{3}$ & $88 \mathrm{~b}$ & $99 \mathrm{a}$ & $99 \mathrm{a}$ \\
\hline Estádio $\mathrm{V}_{4}$ & $90 \mathrm{~b}$ & $97 \mathrm{a}$ & $97 \mathrm{a}$ \\
\hline Estádio $\mathrm{V}_{5}$ & $89 \mathrm{~b}$ & $96 \mathrm{a}$ & $97 \mathrm{a}$ \\
\hline Estádio $\mathrm{V}_{6}$ & $87 \mathrm{~b}$ & $97 \mathrm{a}$ & $97 \mathrm{a}$ \\
\hline Estádio $\mathrm{V}_{7}$ & $89 \mathrm{~b}$ & $97 \mathrm{a}$ & $97 \mathrm{a}$ \\
\hline CV (\%) & 1,05 & 2,31 & 1,84 \\
\hline
\end{tabular}

${ }^{1} \mathrm{DAA}=$ dias após a aplicação do herbicida.

Médias seguidas da mesma letra na coluna não diferem pelo teste de Duncan a $5 \%$ de probabilidade.

dos 14 DAA, as menores porcentagens de controle deram-se nos estádios $\mathrm{V}_{5}$ a $\mathrm{V}_{7}$. Esse menor controle deveu-se ao fato de as plantas daninhas estarem mais desenvolvidas, o que diminui a eficácia do herbicida. Outro aspecto interessante é a redução no controle observado na aplicação realizada no estádio $V_{2}$, em que a avaliação ocorreu aos 21 DAA. Essa diminuição no controle deveu-se ao novo fluxo de emergência de plantas daninhas, as quais reinfestaram a área.

Para picão-preto, a testemunha sem plantas daninhas apresentou o melhor resultado em relação as épocas de controle nos estádios fenológicos $V_{2}$ a $V_{7}$, quando a avaliação foi aos 7 DAA dos herbicidas (Tabela 1). Nas avaliações aos 14 e 21 DAA, as épocas de controle de $V_{2}$ a $\mathrm{V}_{7}$ apresentaram alto grau de controle. Isso demonstra que a mistura dos herbicidas nicosulfuron + atrazine foi eficaz no controle do picão 
nos diferentes estádios de desenvolvimento do milho.

A análise de variância mostrou ser significativa a interação das épocas de aplicação de nitrogênio e dias de contagem das plantas daninhas (Figura 1). Todos os tratamentos foram descritos por uma equação quadrática. Observa-se que os coeficientes de determinação $\left(R^{2}\right)$ foram significativos, apesar de serem baixos e variarem de 0,46 a 0,67 (Figura 1). Isso ocorreu devido ao grande número de pontos e em função da variabilidade da variável avaliada.

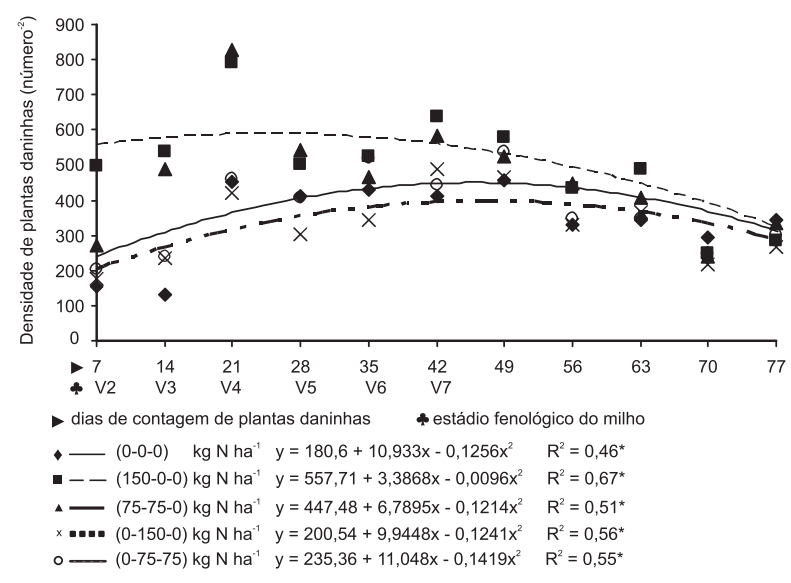

Figura 1 - Densidade de plantas daninhas na testemunha na ausência de controle destas plantas, sob diferentes épocas de aplicação de nitrogênio e dias de contagem de plantas daninhas

Os tratamentos em que o nitrogênio foi aplicado mais precocemente, ou seja, todo na pré-semeadura (150-0-0), e o parcelado parte na pré-semeadura e parte no estádio fenológico $\mathrm{V}_{4}$ (75-75-0) propiciaram maiores densidades de plantas daninhas, em relação aos demais (Figura 1). Essas aplicações antecipadas do nitrogênio causaram decomposição mais rápida da palha da cobertura, e o solo nesta condição ficou mais tempo descoberto. Esta condição estimulou maior emergência das plantas daninhas, resultando em maior densidade. Essas informações são semelhantes às de Blackshaw et al. (2004), que observaram que as densidades de Brassica kaber, Chenopodium album e Avena fatua foram maiores quando o nitrogênio foi aplicado na présemeadura, quando comparado com aplicações na semeadura do trigo. De forma similar, na cultura da cevada, a densidade de Avena fatua foi $25 \%$ maior quando o nitrogênio foi aplicado em pré-semeadura (Scursoni \& Arnold, 2002).

Quanto à matéria seca das plantas daninhas, observou-se interação significativa das épocas de aplicação do nitrogênio e épocas de controle destas plantas (Figura 2). A testemunha sem $\mathrm{N}$ foi descrita pelo modelo polinomial de primeiro grau. Observa-se que, à medida que o controle das plantas daninhas foi atrasado do estádio $V_{2}$ para o $V_{7}$, aumentou $4,4 \mathrm{~kg} \mathrm{ha}^{-1}$ na matéria seca das ervas para cada dia de atraso no controle. Esta testemunha produziu menor massa nas épocas de controle $\mathrm{V}_{2}$ e $\mathrm{V}_{7}$, em relação aos tratamentos que receberam nitrogênio. Esse comportamento já era esperado, tendo em vista a ausência do nitrogênio. Os tratamentos (150-0-0), (75-75$0),(0-150-0)$ e (0-75-75) foram descritos por equações quadráticas negativas, as quais estimaram que as menores quantidades de matéria seca das plantas daninhas ocorreram quando os controles foram realizados no $7^{\circ}$, $17^{\circ}$, $18^{\circ}$, $20^{\circ}$ e $21^{\circ}$ dias após a emergência do milho, respectivamente.

As maiores quantidades de matéria seca das plantas daninhas ocorreram quando o controle foi realizado no estádio $\mathrm{V}_{7}$ do milho (Figura 2). Nessa época, houve menor eficiência de controle das plantas daninhas, pelo fato de que elas tiveram o maior desenvolvimento vegetativo, apresentando barreira fisica, tanto pelas plantas daninhas como pelas culturas, além do aumento da tolerância destas plantas aos herbicidas.

Para o nitrogênio na folha-índice do milho, não houve interação significativa das épocas de aplicação de nitrogênio e épocas de controle de plantas daninhas, ocorrendo diferença significativa entre as épocas de aplicação de $\mathrm{N}$ (Tabela 2). Não houve diferença significativa entre épocas de controle de plantas daninhas.

No tratamento (0-75-75) de aplicação do nitrogênio em cobertura, o teor de nitrogênio na folha-índice do milho foi superior ao dos demais. Comparando o tratamento com nitrogênio (0-75-75) com a testemunha zero de $\mathrm{N}$, o aumento no teor de nitrogênio na folha-índice foi de $91,6 \%$ (Tabela 2). Dhima \& Eleftherohorinos (2001) constataram aumento no nitrogênio total das culturas de trigo, cevada 


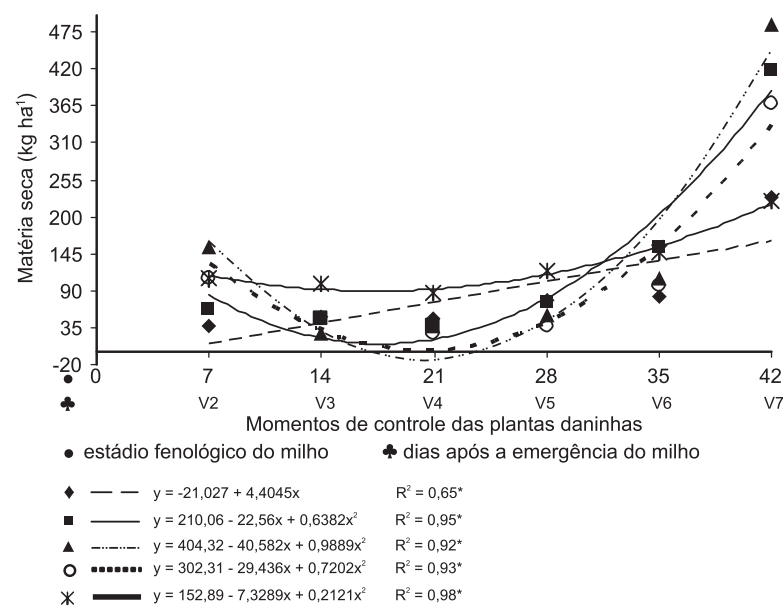

Figura 2 - Matéria seca das plantas daninhas sob diferentes épocas de aplicação de nitrogênio e épocas de controle destas plantas.

Tabela 2 - Teor de nitrogênio na folha-índice da planta de milho sob diferentes épocas de aplicação do $\mathrm{N}$, na média das épocas de controle das plantas daninhas

\begin{tabular}{|l|c|c|}
\hline \multirow{2}{*}{$\begin{array}{c}\text { Época de } \\
\text { aplicação de } \mathrm{N}\end{array}$} & \multicolumn{2}{|c|}{ Nitrogênio } \\
\cline { 2 - 3 } & $\%$ & $\begin{array}{c}\text { Matéria seca } \\
\left(\mathrm{g} \mathrm{kg}^{-1}\right)\end{array}$ \\
\hline$(0-75-75)^{*}$ & $2,05 \mathrm{a}$ & $20,5 \mathrm{a}$ \\
\hline$(0-150-0)$ & $1,93 \mathrm{~b}$ & $19,3 \mathrm{~b}$ \\
\hline$(75-75-0)$ & $1,72 \mathrm{c}$ & $17,2 \mathrm{c}$ \\
\hline$(150-0-0)$ & $1,66 \mathrm{c}$ & $16,6 \mathrm{c}$ \\
\hline$(0-0-0)$ & $1,07 \mathrm{~d}$ & $10,7 \mathrm{~d}$ \\
\hline Média & 1,68 & 16,8 \\
\hline CV $(\%)$ & 11,79 & 11,79 \\
\hline
\end{tabular}

* Doses de $\mathrm{N}$ nas épocas de pré-semeadura, estádio $\mathrm{V}_{4}$ e estádio $\mathrm{V}_{8}$ da cultura do milho, respectivamente.

Médias seguidas de mesma letra na coluna não diferem pelo teste de Duncan a $5 \%$ de probabilidade.

e triticale, quando adubadas com $150 \mathrm{~kg} \mathrm{~N} \mathrm{ha}^{-1}$, independentemente da época de aplicação, comparado com a testemunha sem aplicação de nitrogênio. Observa-se na Tabela 2 que, à medida que a aplicação de nitrogênio foi sendo antecipada, reduziu-se o teor de nitrogênio na folha-índice. No tratamento (0-75-75), o nitrogênio foi aplicado nos estádios fenológicos $\mathrm{V}_{4}$ e $V_{8}$ e o seu fornecimento foi mais próximo das épocas de maior consumo por parte da cultura do milho, resultando em maior disponibilidade desse nutriente.
Em relação a estatura de planta e altura de inserção da espiga de milho, não houve interação significativa das épocas de aplicação de nitrogênio e épocas de controle das plantas daninhas (Tabela 3). A estatura de planta de milho foi superior nos tratamentos (0-75-75) e (0-150-0), enquanto a altura de inserção da espiga foi maior nos tratamentos (75-75-0), (150-0-0) e (0-150-0). Comparando o melhor tratamento com nitrogênio (75-75-0) com a testemunha que não recebeu esse nutriente, o aumento na altura de inserção da espiga foi de $22,6 \%$.

Tabela 3 - Estatura de planta e altura de inserção da espiga de milho sob diferentes épocas de aplicação de $\mathrm{N}$, na média das épocas de controle das plantas daninhas

\begin{tabular}{|l|c|c|}
\hline $\begin{array}{c}\text { Época de } \\
\text { aplicação de N }\end{array}$ & $\begin{array}{c}\text { Estatura de } \\
\text { planta de milho } \\
(\mathrm{m})\end{array}$ & $\begin{array}{c}\text { Altura de } \\
\text { inserção da } \\
\text { espiga }(\mathrm{m})\end{array}$ \\
\hline$(0-75-75)^{*}$ & $2,10 \mathrm{a}$ & $1,14 \mathrm{a}$ \\
\hline$(0-150-0)$ & $2,10 \mathrm{a}$ & $1,11 \mathrm{ab}$ \\
\hline$(150-0-0)$ & $2,06 \mathrm{~b}$ & $1,11 \mathrm{ab}$ \\
\hline$(75-75-0)$ & $2,03 \mathrm{c}$ & $1,10 \mathrm{~b}$ \\
\hline$(0-0-0)$ & $1,88 \mathrm{~d}$ & $0,93 \mathrm{c} 0$ \\
\hline Média & 2,03 & 1,07 \\
\hline CV $(\%)$ & 3,04 & 4,86 \\
\hline
\end{tabular}

* Doses de $\mathrm{N}$ nas épocas de pré-semeadura, estádio $\mathrm{V}_{4}$ e estádio $\mathrm{V}_{8}$ da cultura do milho, respectivamente.

Médias seguidas da mesma letra não diferem pelo teste de Duncan a $5 \%$ de probabilidade.

A estatura de planta de milho decresceu à medida que o controle das plantas daninhas foi realizado em estádio fenológico mais avançado (Figura 3). Isso pode ser explicado pelo fato de que elas tiveram menor disponibilidade dos recursos para crescimento, resultando nas menores estaturas. A maior estatura de planta foi obtida quando o controle das plantas daninhas foi realizado no estádio fenológico $V_{2}$. Resultados similares foram encontrados por Zagonel et al. (2000).

Também, de forma semelhante ao observado para estatura, a altura de inserção da espiga decresceu à medida que a época de controle foi realizada num estádio fenológico mais avançado (Figura 4). Esta foi maior quando o controle das plantas daninhas foi realizado no 


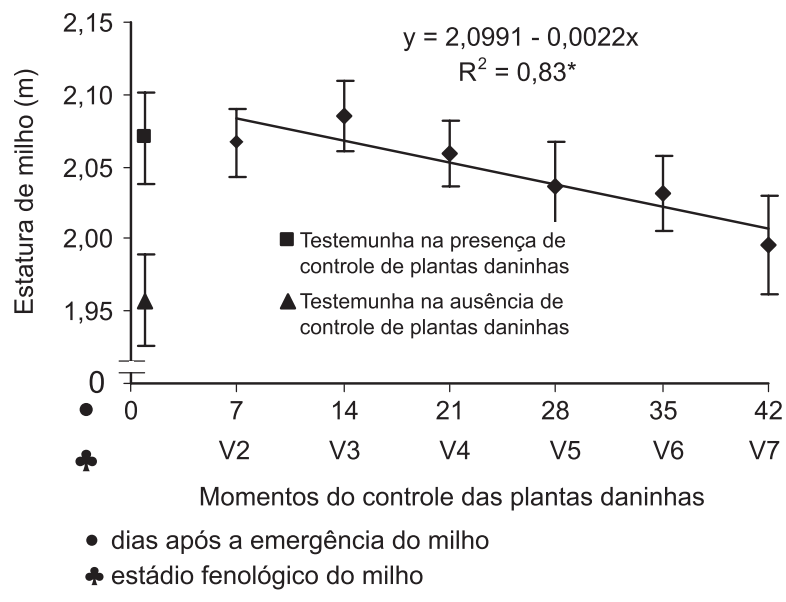

Figura 3 - Estatura de planta de milho sob diferentes épocas de controle das plantas daninhas, na média das épocas de aplicação do nitrogênio. (Barras verticais representam o erro-padrão da média).

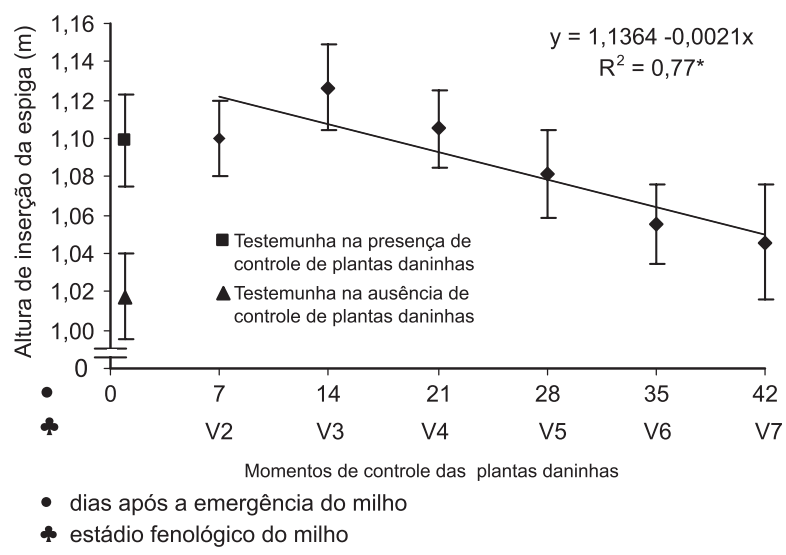

Figura 4 - Altura de inserção da espiga de milho sob diferentes épocas de controle das plantas daninhas, na média das épocas da aplicação do nitrogênio. (Barras verticais representam o erro-padrão da média).

estádio fenológico $\mathrm{V}_{2}$. Isso pode ser explicado pelo fato de a cultura do milho ter sofrido competição pelas condições ambientais, como água, luz e nutrientes.

Quanto ao rendimento de grãos, não houve interação significativa das épocas de aplicação de nitrogênio e épocas de controle das plantas daninhas, tendo somente ocorrido diferenças significativas entre as épocas de aplicação de $\mathrm{N}$ e as épocas de controle de plantas daninhas.

O menor rendimento foi na testemunha zero de N, conforme já era esperado, pois ela não recebeu nitrogênio (Tabela 4). Nos trata-
Tabela 4 - Rendimento de grãos, peso de mil grãos e número de grãos por espiga de milho sob diferentes épocas de aplicação de $\mathrm{N}$, na média das épocas de controle das plantas daninhas

\begin{tabular}{|l|c|c|c|}
\hline $\begin{array}{c}\text { Época de } \\
\text { aplicação de } \\
\mathrm{N}\end{array}$ & $\begin{array}{c}\text { Rendimento } \\
\text { de grãos } \\
\left(\mathrm{kg} \mathrm{ha}^{-1}\right)\end{array}$ & $\begin{array}{c}\text { Peso de mil } \\
\text { grãos } \\
(\mathrm{g})\end{array}$ & $\begin{array}{c}\text { Número de } \\
\text { grãos por } \\
\text { espiga }\end{array}$ \\
\hline$(0-75-75)^{*}$ & $9.984 \mathrm{a}$ & $355 \mathrm{a}$ & $467 \mathrm{a}$ \\
\hline$(0-150-0)$ & $9.921 \mathrm{a}$ & $348 \mathrm{~b}$ & $464 \mathrm{a}$ \\
\hline$(75-75-0)$ & $9.619 \mathrm{ab}$ & $340 \mathrm{c}$ & $464 \mathrm{a}$ \\
\hline$(150-0-0)$ & $9.346 \mathrm{~b}$ & $332 \mathrm{~d}$ & $460 \mathrm{a}$ \\
\hline$(0-0-0)$ & $5.475 \mathrm{c}$ & $295 \mathrm{e}$ & $310 \mathrm{~b}$ \\
\hline Média & 8.682 & 334 & 433 \\
\hline CV (\%) & 8,78 & 4,25 & 9,27 \\
\hline
\end{tabular}

* Doses de $\mathrm{N}$ nas épocas de pré-semeadura, estádio $\mathrm{V}_{4}$ e estádio $\mathrm{V}_{8}$ da cultura do milho, respectivamente.

Médias seguidas da mesma letra não diferem pelo teste de Duncan a $5 \%$ de probabilidade.

mentos que receberam nitrogênio, o menor rendimento ocorreu quando o nutriente foi aplicado totalmente na pré-semeadura (1500-0). Esse resultado ocorreu provavelmente pela menor disponibilidade de nitrogênio na fase final da cultura. Para atingir elevados rendimentos, é importante que este nutriente continue disponivel até os estádios entre 12 folhas e grãos leitosos, pois é quando se confirma o potencial de produção, o qual foi definido precocemente.

Os maiores rendimentos de grãos de milho foram obtidos nos tratamentos (0-75-75) e (0-150-0), porém sem diferir estatisticamente do tratamento (75-75-0) (Tabela 4). Comparando o tratamento com nitrogênio (0-75-75) com a testemunha zero de $\mathrm{N}$, o aumento no rendimento foi de $82 \%$.

Em relação ao efeito da época de controle sobre o rendimento de grãos, observou-se que este foi descrito por uma equação polinomial de segundo grau, com $R^{2}$ de 0,91 (Figura 5). Constata-se que a melhor época de controle das plantas daninhas foi no $20^{\circ}$ dia após a emergência, o qual corresponde ao estádio fenológico $\mathrm{V}_{4}$. Quando o controle das plantas daninhas foi realizado precocemente, em $V_{2}$, o rendimento foi reduzido, pois o controle precoce propiciou a reinfestação das ervas. Já quando o controle foi efetuado tardiamente, em $\mathrm{V}_{7}$, o rendimento foi o menor, devido à reduzida eficácia dos herbicidas, uma vez que as ervas se apresentavam mais desenvolvidas, conseqüentemente mais tolerantes ao herbicida. 


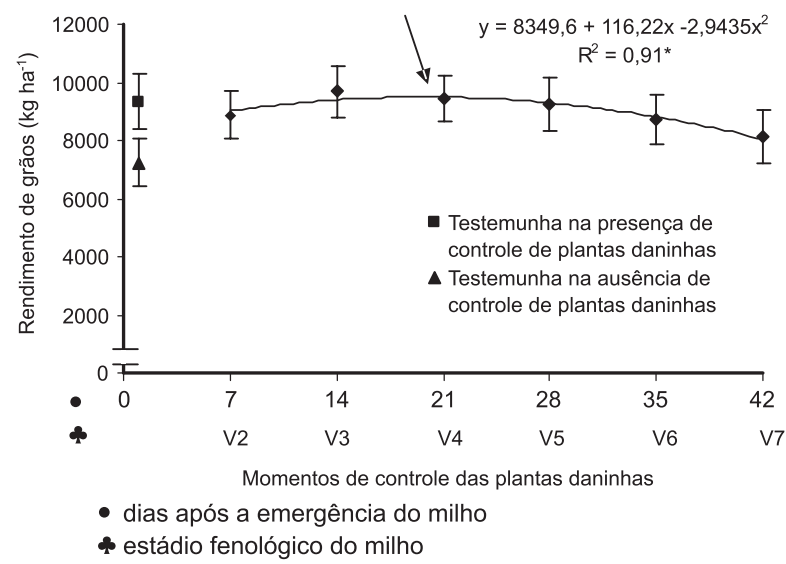

Figura 5 - Rendimento de grãos de milho sob diferentes épocas de controle das plantas daninhas, na média das épocas de aplicação do nitrogênio. (Barras verticais representam o erro-padrão da média)

Na cultura do milho, Hans \& Johnson (2002) obtiveram curva linear decrescente, na presença de Sorghum bicolor. Também no milho, o maior rendimento de grãos ocorreu quando o controle das plantas daninhas poáceas foi realizado na época em que as plantas de milho estavam no estádio fenológico $V_{5}$ no primeiro ano $\mathrm{e}_{6}$ no segundo ano, independentemente das épocas de aplicação do nitrogênio (Hellwig et al., 2002). Resultados indicam que os maiores rendimentos de grãos ocorrem quando o controle das plantas daninhas é efetuado nos estádios $\mathrm{V}_{2}$ e $\mathrm{V}_{3}$ da cultura (Rizzardi et al., 2006).

Quanto ao acréscimo de rendimento de grãos em relação à testemunha sem controle das plantas daninhas, não houve interação significativa das épocas de aplicação de nitrogênio e épocas de controle. Contudo, houve efeito das épocas de controle das plantas daninhas. A equação obtida estimou que o ponto máximo de acréscimo de rendimento de grãos foi observado na época em que o controle de plantas daninhas foi realizado no 20 dia após a emergência do milho, o qual correspondeu ao estádio fenológico do milho $\mathrm{V}_{4}$ (Figura 6). Em trabalho conduzido por Rizzardi \& Silva (2006) foi observado que o maior acréscimo de rendimento se deu no controle realizado no $18^{\circ}$ dia após emergência do milho, o qual correspondeu ao estádio fenológico $\mathrm{V}_{3}$.

Os resultados de peso de grãos indicam que o tratamento (0-75-75) foi significativamente superior aos demais, e, como já era esperado,

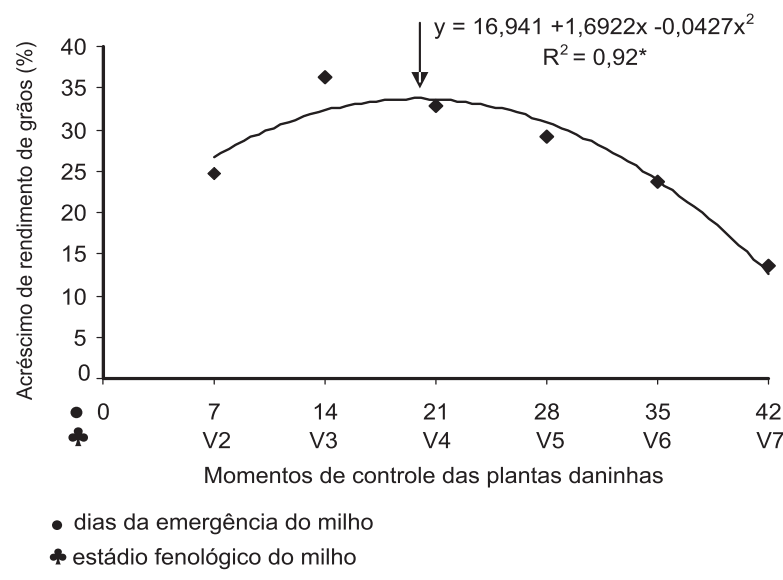

Figura 6 - Acréscimo de rendimento de grãos de milho em relação à testemunha sem controle das plantas daninhas sob diferentes épocas de controle destas plantas, na média das épocas de aplicação do nitrogênio.

a testemunha sem $\mathrm{N}$ teve peso inferior (Tabela 4). Nos tratamentos que receberam nitrogênio, obtiveram-se valores inferiores de peso de grãos quando o nutriente foi aplicado totalmente na pré-semeadura (150-0-0). A aplicação precoce do nutriente pode ter ocasionado perdas por lixiviação, devido à precipitação elevada durante o ciclo da cultura. A menor disponibilidade do nitrogênio durante o período de enchimento de grãos refletiu negativamente no peso de grãos. Comparando este tratamento com o tratamento (150-0-0), o aumento no peso de mil grãos foi de $6,9 \%$. Comparando o tratamento (0-75-75) com a testemunha sem N, o aumento no peso de mil grãos foi de $20,3 \%$.

Para número de grãos por espiga, somente ocorreram diferenças significativas entre as épocas de aplicação de $\mathrm{N}$ e entre as épocas de controle das plantas daninhas. Os tratamentos que receberam nitrogênio foram superiores à testemunha sem aplicação deste nutriente. Isso pode ser explicado pelo fato de que o nitrogênio se encontrava em níveis adequados na etapa de confirmação do número de fileiras da espiga, entre os estádios fenológicos $V_{7}$ e $\mathrm{V}_{\mathrm{g}}$. Comparando o tratamento com nitrogênio (75-75-0) com a testemunha zero de N, o acréscimo no número de grãos por espiga foi de $50,6 \%$. Nos tratamentos que receberam nitrogênio o número de grãos por espiga variou de 460 a 467 (Tabela 4).

No que se refere ao número de grãos por espiga, observa-se comportamento quadrático 
com o atraso na época de controle (Figura 7). Ao se observar a curva de ajuste, percebe-se que o maior número de grãos por espiga foi obtido quando o controle foi feito no estádio fenológico $\mathrm{V}_{4}$, o que coincidiu com os maiores acréscimos de rendimento obtidos (Figura 6).

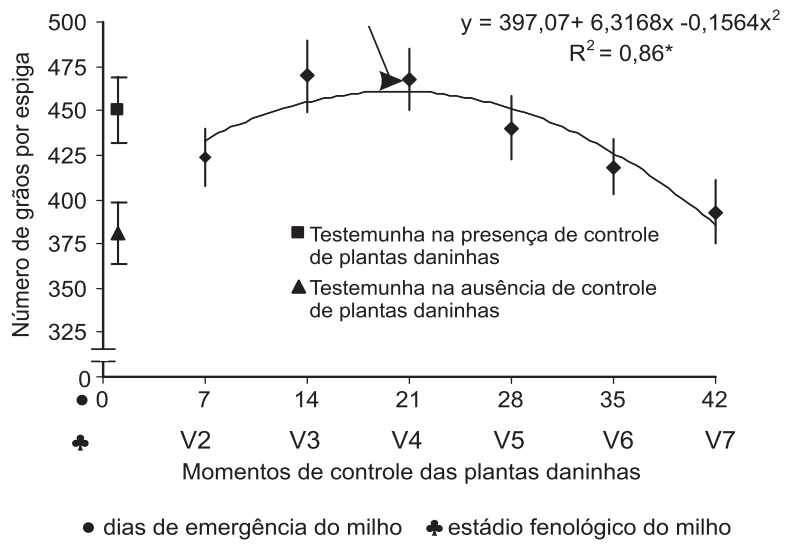

Figura 7 - Número de grãos por espiga de milho sob diferentes épocas de controle das plantas daninhas, na média das épocas de aplicação do nitrogênio. (Barras verticais representam o erro-padrão da média).

A hipótese deste trabalho - de que a época de aplicação do nitrogênio afeta a disponibilidade deste nutriente no sistema e influi tanto na época de controle quanto no espectro das plantas daninhas - foi comprovada. Isso mesmo não havendo interação entre épocas de aplicação do nitrogênio e épocas de controle de plantas daninhas, para a maioria das variáveis estudadas, com exceção da densidade de plantas daninhas na testemunha na ausência de controle e da matéria seca das plantas daninhas. Saliente-se que as várias épocas de aplicação de nitrogênio resultaram em diferentes densidades das plantas daninhas, e aplicações antecipadas do nutriente aumentaram a densidade das ervas. Além disso, concluiu-se que a época de aplicação do nitrogênio influenciou a melhor época de controle, resultando em menor produção da matéria seca das plantas daninhas.

\section{LITERATURA CITADA}

BALL, D. A.; WYSOCKI, D. J.; CHASTAIN, T. G. Nitrogen application timing effects on downy brome (Bromus tectorum) and winter wheat (Triticum aestivum) growth and yield. Weed Technol., v. 10, n. 2, p. 305-310, 1996.
BLACKSHAW, R. E.; MOLNAR, L. J.; JANZEN, H. H Nitrogen fertilizer timing and application method affect weed growth and competition with spring wheat. Weed Sci., v. 52, n. 4, p. 614-622, 2004.

DHIMA, K. V.; ELEFTHEROHORINOS, I. G. Influence of nitrogen on competition between winter cereals and sterile oat. Weed Sci., v. 49, n. 1, p. 77-82, 2001.

DITOMASO, J. M. Approaches for improving crop competitiveness through the manipulation of fertilization strategies. Weed Sci., v. 43, n. 5, p. 491-497, 1995.

FLECK, N. G.; SILVA, P. R. F. Efeitos de épocas de aplicação de nitrogênio em cobertura na cultura do girassol, com e sem controle de plantas daninhas. Pesq. Agropec. Bras., v. 24, n. 6, p. 669-676, 1989.

HANS, S. R.; JOHNSON, W. G. Influence of shattercane [Sorghum bicolor (L.) Moench.] interference on corn (Zea mays L.) yield and nitrogen accumulation. Weed Technol., v. 16, n. 4 , p. $787-791,2002$.

HARBUR, M. M.; OWEN, M. D. K. Response of three annual weeds to corn population density and nitrogen fertilization timing. Weed Sci., v. 52, n. 5, p. 845-853, 2004

HELLWIG, K. B.; JOHNSON, W. G.; SCHARF, P. C. Grass weed interference and nitrogen accumulation in no-tillage corn. Weed Sci., v. 50, n. 6, p. 757-762, 2002.

PAOLINI, R. et al. Competition between sugarbeet and Sinapis arvensis and Chenopodium album, as affected by timing of nitrogen fertilization. Weed Res. v. 39, n. 5, p. $425-440,1999$.

RIZZARDI, M. A.; SILVA, L. F. Influência das coberturas vegetais antecessoras de aveia-preta e nabo forrageiro na época de controle de plantas daninhas em milho. Planta Daninha, v. 24, n. 4, p. 669-675, 2006.

RIZZARDI, M. A.; SILVA, L. F.; VARGAS, L. Controle de plantas daninhas em milho em função de quantidades de palha de nabo forrageiro. Planta Daninha, v. 24, n. 2, p. $263-270,2006$

SCURSONI, J. A.; ARNOLD, R. B. Effect of nitrogen fertilization timing on the demographic processes of wild oat (Avena fatua) in barley (Hordeum vulgare). Weed Sci., v. 50, n. 5 , p. $616-621,2002$.

WALKER, R. H.; BUCHANAN, G. A. Crop manipulation in integrated weed management systems. Weeds Sci., v. 30, p. 17-24, 1982. (Suplemento)

ZAGONEL, J.; VENÂNCIO, W. S.; KUNZ, R. P. Efeitos de métodos e épocas de controle das plantas daninhas na cultura do milho. Planta Daninha, v. 18, n. 1, p. 143-150, 2000 .

Planta Daninha, Viçosa-MG, v. 26, n. 1, p. 113-121, 2008 